\title{
THE RELATIONSHIPS BETWEEN INTANGIBLE ORGANIZATIONAL ELEMENTS AND ORGANIZATIONAL PERFORMANCE
}

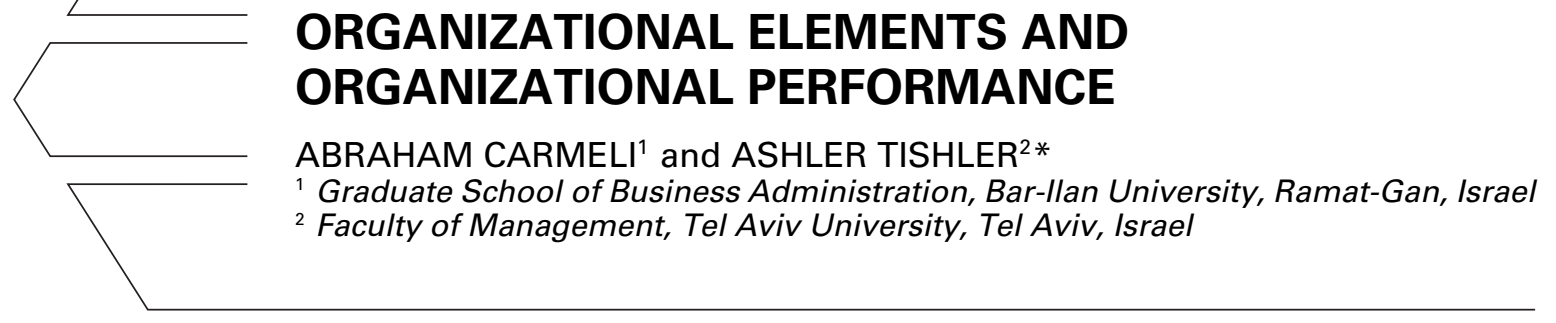

\begin{abstract}
Despite the growing awareness of the importance of researching core strategic resources and activities, the work that has been done to date has largely taken the form of anecdotal reports and case study analysis. We have yet to see large-sample studies demonstrating how organizational elements, independently, complementarily and interactively, may or may not enhance the organization's performance. Moreover, little attention has been given to researching this topic in public sector organizations. The present study aims to bridge this gap by examining the impact of a set of independent intangible organizational elements and the interactions among them on a set of objective organizational performance measures in a sample of local government authorities in Israel. The results of a multivariate analysis indicate that organizational performance (measured by self-income ratio, collecting efficiency ratio, employment rate, and municipal development) can be well explained by six intangible organizational elements (managerial capabilities, human capital, internal auditing, labor relations, organizational culture, and perceived organizational reputation) and the interactions among them, which need to be taken into account in any cost effective development. Copyright (c) 2004 John Wiley \& Sons, Ltd.
\end{abstract}

\section{INTRODUCTION}

Recognizing that organizations, whether for-profit, governmental or non-profit, are complex entities, researchers often describe and analyze them as systems of interdependent core elements (resources, activities, and policies) (see Porter, 1996; Rivkin, 2000; Siggelkow, 2002) that by complementing one another contribute to enhancing and sustaining competitive advantages. The problem is that measuring core resources and their effect on organizational performance is often difficult (see Hoskisson

Keywords: intangible organizational elements; complementarities; organizational performance; public sector organization

${ }^{*}$ Correspondence to: Ashler Tishler, Faculty of Management, Tel Aviv University, Ramat Aviv, Tel Aviv 69978, Israel.

E-mail: atishler@post.tau.ac.il et al., 1999; Robins and Wiersema, 1995), particularly when one needs to estimate the effect of a possibly large set of intangible resources with all manner of possible complementarities and interactions among them, on a possibly large set of organizational performance measures. Though anecdotal and case study evidence does exist (Porter, 1996; Siggelkow, 2002; Stalk, Evans, and Shulman, 1992), we have not yet seen large-sample studies that demonstrate how several core elements, independently or together, enhance organizational performance.

Substantial effort has been devoted in the last decade to enhancing the theoretical insights of the resource-based view (RBV) of strategic management, which serves as the paradigm of this study, and examining it empirically in profitmaximizing firms (see Barney, 2001, for a partial review). Generally, the design of most quantitative 
RBV studies has employed a single major factor (resource) to explain variations in firm performance, which often consist of a single measure. Moreover, studies applying the core concepts of the RBV in general and testing the effect of strategic elements on the performance of public sector organizations are rare.

This study attempts to bridge these gaps by using a quantitative method to empirically test the effect of intangible core elements (resources) on the performance of public sector organizations. We first argue that the RBV can serve as a useful paradigm for the analysis of variations in the performance of public sector organizations and then empirically test our approach on a sample of 99 local government authorities in Israel. Specifically, we estimate the influence of a set of intangible elements and their interactions on a set of performance measures while controlling for the effects of environmental uncertainty, organization size, and geographical location. The intangible elements are managerial capabilities, human capital, perceived organizational reputation, internal auditing, labor relations, and organizational culture, and performance is evaluated by two measures of financial performance, the employment rate, a measure of municipal development, and internal migration.

The findings, which lend support to the premise that intangible elements have a significant effect on organizational performance, are especially important considering that we estimate the simultaneous impact of a set of intangible elements on a set of several performance measures. All six organizational elements and all the interactions among them are found to be important in explaining the variations in the performance of local authorities. The positive effect of the interactions among the organizational elements on organization performance is such that the higher the values of the other intangible organizational elements, the larger the effect of any given intangible organizational element. Organizational culture and perceived organizational reputation are found to be the two most important elements in explaining organizational performance. Size has little or no effect, while perceived environmental uncertainty and geographical location are important factors in explaining variations in organizational performance.

The study is organized as follows. The next section presents the theoretical and methodological aspects of the resource-based view in general and in the public sector in particular, and develops the research hypotheses. The research method-participants, measures, and data analysis - is in the third section, followed by the results of this study. The final section includes a discussion of the results, an analysis of the study's limitations, and suggestions for directions of future research.

\section{THEORY AND HYPOTHESES}

Organizations are viewed as systems of core, elaborating, independent, and inconsistent elements and the interconnections among all or part of these elements (Siggelkow, 2002). The elements denoting resources, activities, processes, and policies are essential for the viability of the organization. Although studies that have examined the core concepts of the resource-based view (RBV) have generally used three main constructs - resources, capabilities, and competencies (Javidan, 1998)they have tended to refer to those that are core to the organization in the sense of contributing to differentiating it strategically from its rivals (Leonard-Barton, 1992). In this study we use the construct of strategic organizational element (resource) to refer to a special type ${ }^{1}$ of element which is unique, imperfectly imitable, nontransferable and aims to improve the productivity of the organization (Makadok, 2001) independently or through a process of interacting with other elements.

The RBV suggests that the variability in an organization's performance can be attributed to heterogeneity in the distinct bundles of organizational elements (resources) (Barney, 1991; Peteraf, 1993; Prahalad and Hamel, 1990; Reed and DeFillippi, 1990; Wernerfelt, 1984). Though the RBV has clearly made a powerful impact in the field of strategy, scholars question the extent to which it may be considered as a paradigm in the field (see Barney, 2001; Priem and Butler, 2001). Notably, a decade ago, Peteraf (1993: 179) asked whether the RBV 'provides much additional insight over traditional understandings.' Although she and others (Barney, 2001) have advocated the RBV as a paradigm, the debate has not yet been resolved, particularly in the face of the lack

\footnotetext{
${ }^{1}$ The term 'special type' is taken from the work of Makadok, who refers to a capability as a special type of resource (Makadok, 2001: 389).
} 
of sufficient empirical studies to lend support to the RBV's theoretical propositions (see Farjoun, 1994). Though in recent years we have been observing an increased effort to develop an empirical body of literature on the RBV (see Barney, 2001 , for a review), it remains an area that can benefit from additional study. First, most quantitative studies have used a single element such as human capital (e.g., Hitt et al., 2001) or leadership (e.g., Waldman et al., 2001). Although such studies yield useful knowledge, it must be recognized that the organization's competitive position is derived from a complex combination of organizational elements. Generally speaking, it is not likely that a firm with a sustainable competitive advantage relies on a single element, important as it may be. For example, the competitive advantage of Wal-Mart (Stalk et al., 1992), Southwest (Porter, 1996), and Vanguard (Siggelkow, 2002) cannot be explained by just one element; it is based on a successful integration of various strategic and non-strategic elements. Whereas rivals are enthusiastic to imitate such successful designed system, the organizations that hold it seek ways to deter such imitation. What makes a system inimitable? Rivkin (2000) suggests that the number of elements and the degree of interaction among them create such a complexity that is difficult to imitate by the rivals. By having a large number of elements that positively interact with one another a firm can deter imitation even if each particular element is imitable (Rivkin, 2000).

The problem is that our knowledge to date is contained in anecdotal and case study evidence (see, for example, Porter, 1996; Siggelkow, 2002; Stalk et al., 1992), and we have yet to see large-sample studies that demonstrate how strategic elements and complementarities among them enhance an organization's performance. The second problem is the difficulty of measuring these compellingly important intangible elements (see Godfrey and Hill, 1995; Hitt et al., 2001). This problem is compounded when more than one element is involved and, particularly, when interactions among them may affect the organization's performance. Third, most studies have examined each performance measure separately and, thus, did not capture the simultaneity embedded in the multidimensionality of performance. Fourth, very little has been done to test empirically the relationship between organizational elements and the performance of public sector organizations, that is, the applicability of the basic elements of the RBV in the public sector. This is particularly problematic in view of the increasing recognition among researchers, policy-makers and managers alike of the importance of strategic management, whether in the private or public sector, for creating and delivering value (Moore, 1995, 2000).

This study of local government authorities attempts to overcome some of the limitations of previous studies by adopting a multivariate approach in which a bundle of intangible organizational elements and the interactions among them are examined for their simultaneous effect on several measures of performance.

\section{The impact of intangible organizational elements}

Both tangible elements (e.g., facilities, raw materials, equipment) and intangible elements (e.g., culture, communication, and knowledge) have an important role in creating an organization's value. However, 'as the industrial society becomes a services society, where knowledge and information are the mainstays of business growth, the importance of intangible resources will come increasingly to the forefront' (Canals, 2000: 118). In comparison with tangible elements, intangible elements such as organizational culture are less flexible (Chatterjee and Wernerfelt, 1991), hard to accumulate, and not easily transferred; they can affect multiple uses at the same time, serve simultaneously as inputs and outputs of corporate activities (Itami with Roehl, 1987), and are not consumed when in use (Collis and Montgomery, 1998). Teece (2000) suggests that a firm's superior performance depends on its ability to defend and use the intangible assets it creates (e.g., knowledge). According to Hitt et al. (2001: 14), "intangible resources are more likely than tangible resources to produce a competitive advantage.'

Drawing on these insights, according to which intangible elements have strategic importance for the viability of the organization, this study focuses on a set of six intangible elements and their effect on the performance of the organization: managerial capabilities, human capital, perceived organizational reputation, internal auditing, labor relations, and organizational culture.

We chose to concentrate on these six elements on the basis of a pre-test we made. First, we interviewed central government officials with a view 
to identifying the key factors that influence fiscal health, education, migration, and other performance aspects of local government. Second, we interviewed the heads and senior officials of local government authorities to elicit their perceptions of the elements that are critical to the management of their local authority. Third, we reviewed the relevant literature in order to select the most important elements needed for management of organizations in general and local authorities in particular. Finally, we administered a pilot questionnaire, structured on the basis of the list of elements obtained in steps one to three above, to 13 managers who participated in an annual meeting of the general managers of the local government authorities in Israel. This process identified the six critical elements that we use in this paper to assess organizational performance. Other possible critical elements are noted in the limitations subsection.

We now give a reasoned account of the critical role of the six particular elements that we chose as the basis for our study.

\section{Managerial capabilities}

It has long been established that a superior top management team is likely to generate higher rent for its organization (Barney, 1991; Castanias and Helfat, 1991; Finkelstein and Hambrick, 1996; Hambrick and Mason, 1984; Katz, 1974; Norburn and Birley, 1988; Penrose, 1959). The management team's superiority rests on the managerial capabilities or skills that it possesses because 'the attributes of the management team may satisfy the conditions for achieving and maintaining competitive advantage' (Mahoney, 1995: 92). Attaining superiority in a particular competitive market requires that the organization's top management possesses a broad set of complementary skills. A single person, however talented, is unlikely to possess all the managerial skills that are required for the successful operation of a complex organization. Thus, the organization needs to have a combination of capabilities (Barney, 1991; Mahoney, 1995), such as technical, human, and conceptual skills (Katz, 1974) in order to build a superior management team.

\section{Human capital}

The idea that an organization's members are the real source of its competitive advantage has long been acknowledged (Pfeffer, 1994), hence the drive to establish the superior human capital to generate a competitive advantage (e.g., Boxall and Steeneveld, 1999; Farjoun, 1994; Huselid, 1995; Lado and Wilson, 1994; Pfeffer, 1994). Researchers seeking to establish a theoretical framework for the contribution of the human factor to organizational efficiency and effectiveness have focused on the educational level of employees as a source of labor productivity and economic growth for the organization and the nation (Asefa and Huang, 1994; Becker, 1993; Hershberg, 1996; OECD, 2001; Schultz, 1961).

\section{Perceived organizational reputation}

A favorable organizational reputation is a core intangible resource that creates competitive advantage when competitors are not able to match the prestige and esteem it creates, and enables an organization to attain sustained superior outcomes (Roberts and Dowling, 2002; Shrum and Wuthnow, 1988). Constituents always prefer to enter into a contract with an organization with a favorable reputation, and sometimes they are even willing to pay a reasonable premium to do so (Fombrun, 1996; Fombrun and Shanley, 1990; Weigelt and Camerer, 1988); residents and businesses are likely to select their location on the basis of the match between their expectations and the reputation of the local authority. A distinction is made between the organization's reputation and the perceived external prestige (Smidts, Pruyn, and van Riel, 2001) or construed external image (Dutton, Dukerich, and Harquail, 1994). Whereas organizational reputation refers to outsiders' beliefs about what distinguishes an organization, perceived external prestige and construed external image refer to the organizational members' view of the outsiders' beliefs. Assuming that the CEO (or general manager), as the representative of the management team, has the ability to correctly assess the organization's reputation, we use the term perceived organizational reputation to mean top management's view of the outsiders' beliefs about the organization.

\section{Internal auditing}

Internal auditing is a process that examines and evaluates the functioning of the organization (Eden 
and Moriah, 1996: 263). It is an ongoing process of comparing actual performance with standards or expectations, based on relevant indexes, in order to improve the organization's achievements (Globerson and Globerson, 1990). An internal auditing system plays an important role in managing the organization efficiently and effectively. It is extremely important in complex organizations because of the need to pinpoint and examine a large array of activities in order to (1) teach the organization's members how to execute their job better by pointing out weaknesses, (2) enhance the motivation of the organization's members by demonstrating that the audit's goal is to improve the efficiency and effectiveness of the organization, (3) deter members from actions that may damage the organization, and (4) increase the probability that the appropriate actions are taken in relation to goal setting and accomplishment (Eden and Moriah, 1996).

\section{Labor relations}

Labor relations are to the relationships between the management team and the employees and/or their representatives. Organizations with positive labor relations are likely to obtain high benefits from their employees (see Dastmalchian, Blyton, and Adamson, 1991, for a review). For example, labor relations may affect the level of the employees' commitment to the organization. Committed employees are more likely to produce high-yield outcomes, and have a positive effect on organizational performance (Meyer and Allen, 1997).

\section{Organizational culture}

Organizational culture refers to the 'underlying values, beliefs, and principles that serve as a foundation for the organization's management system as well as the set of management practices and behaviors that both exemplify and reinforce those basic principles' (Denison, 1990: 2). Klein, Masi, and Weidner (1995) place organizational culture at the heart of an organization's endeavors to improve its overall effectiveness and the quality of its products and services. Many strategy researchers (e.g., Barney, 1986) assert that organizational culture is an important source of competitive advantage. Much of the evidence from both the private and the public sector supports this argument. For example, Nordstrom, one of America's most successful fashion retailers, ascribes its success to its unique culture of customer service, or, as it is often called, 'the Nordstrom way' (see Spector and McCarthy, 1995).

Virtually none of the successful organizations, from either the private or the public sector, will attribute its success to just one strategic element. Superior organizational performance is due to the combination of several strategic elements that complement and strengthen one another. Given the importance of the intangible elements, we suggest the following hypothesis:

Hypothesis 1: Intangible organizational elements (managerial capabilities, human capital, perceived organizational reputation, internal auditing, labor relations and organizational culture) have a significant, positive effect on the performance of the organization (as measured by financial performance, municipal development, internal migration, and employment rate).

\section{Interactions among intangible organizational elements}

The concept of fit has a long tradition in strategy literature (Itami with Roehl, 1987). Strategic fit, unlike specification of an individual element, indicates nets of tightly linked elements (Porter, 1996) that become a major source of inimitability (Rivkin, 2000) and contribute to enhancing the performance of an organization. Porter (1996) identifies three types of fit: (1) simple consistency between each activity and the overall strategy, (2) mutual reinforcement amongst activities, and (3) optimization of effort across activities. Much of the literature refers to elements that reinforce one another. That is, the interaction amongst them is complementary in that the value of one element is increased by the presence of other elements (see Rivkin, 2000; Siggelkow, 2002). The recent study by Makadok (2003) demonstrated the strategic implication of a synergistic interaction between governance and competence (similar, for instance, to the interaction between managerial competence and internal auditing/control in this study), arguing that superior firms (e.g., Microsoft, Wal-Mart, Crown Cork \& Seal, and Vanguard Group) are 'frequently unusual in both their competence and their governance.'

Hence, it can be hypothesized that a strategic, or core, element is likely to interact with one or 
more other elements in affecting organizational performance. Given the importance we attribute to the six intangible elements that are discussed in this study, we suggest the following hypothesis:

Hypothesis 2: The interactions among the intangible organizational elements enhance organizational performance; that is, the effect of an intangible organizational element is higher, the higher are the values of the other intangible organizational elements.

\section{THE DATA AND THE RESEARCH METHODOLOGY}

\section{Selecting the research population}

Researchers have recognized the importance of public sector organizations and sought to examine the generalizability of the core concepts of business strategy to the public sector (see Moore, 1995; Porter, 1998). Here we choose to investigate the local government sector in Israel because of its critical impact on the business sector, the social structure of the country, and its citizens. Though building viable organizations is clearly a focal subject of inquiry not just for the business sector but also for the public and not-for-profit sectors, applying the core concepts of business strategy to the public sector depends on the type of competition in this sector and its magnitude. We argue here that competition does indeed exist among organizations in the local government sector, and can sometimes even be very intense (see Tiebout, 1956). The consensus is that competition in general fosters economic development by yielding better production efficiency. It is the relentless drive of the competitors to find and apply new ways to improve productivity that is the source of the firm's profitability, the wealth of the state and the world (Porter, 1998). The possibility of obtaining more and better output from the same tangible resources is the foundation of the argument for some type of competition in the public sector (Propper and Halonen, 1999).

That being said, the nature of the competition in the public sector needs some clarification. In general, 'the local market for public goods is really a "quasi market" in which the benefits of competitive markets may be approached but not fully achieved' (Schneider, 1989). A local authority normally provides services only to residents within its jurisdiction, and they are the drivers of the competition among local authorities as they seek to maximize the benefit/cost ratio of their location by buying into local authorities that offer the package of services they most prefer at the most reasonable price in terms of the taxes they pay (Schneider, 1989: 613). If a local authority does not meet its consumers' needs and expectations, it is likely to lose desirable consumers to other local authorities (Peterson, 1981; Schneider, 1989), and its head (mayor) is likely not to be re-elected. The desire to be re-elected is a major driver of the competition as the local authority heads do whatever they can to be perceived as successful.

Though competition among local authorities can be staged on many fronts, in the resource and product market alike, in this study we concentrate on competition in the resource market. Public sector organizations compete over unique and valuable resources that can enhance their capacity-one of the sides of the JFK School of Government's strategic triangle for public sector organizations (see Moore, 1995). Thus, government authorities compete on prestige in key areas, presuming that it will generate rent by attracting new businesses and a strong population, leading eventually to sound fiscal health. They also invest considerable effort in building a strong organizational culture that will enhance the quality of the services they provide to their residents. It is in this way that the fierce competition between the cities of Ramat Gan and Tel Aviv, located in the center of Israel, to attract businesses to their jurisdictions has resulted in better incentive packages being offered by both cities. These incentives are not restricted to discounts in property tax, but lie rather in the unique capacity to provide better services. Similarly, the cities in Coachella Valley, located approximately 120 miles east of Los Angeles, have been competing over land for future growth and outside investment. ${ }^{2}$

Appropriate performance measures are critical for any organization, and even more so for public sector organizations. To quote The National Academy of Public Administration of the United States (1999: 17): 'The American people will not invest significantly higher levels of trust or confidence in their government until they perceive improvements in the way it makes decisions and

\footnotetext{
${ }^{2}$ We are indebted to Lynndee Kemmet for providing us with her unpublished comprehensive study on the Coachella Valley situation.
} 
delivers results.' Local authorities are complex organizations that serve multiple constituencies and are accountable for various functional areas such as education, employment, municipal development, recreation, and sanitation. Hence, it is of importance to develop appropriate performance criteria upon which these multiple and complicated tasks are evaluated. These measures are not readily available in Israel since the Israeli local authorities do not systematically publish assessments or measures of their performance (Carmeli, 2002), making evaluation a very difficult task. In this study we developed five performance measures, for two consecutive years, based on secondary data.

\section{Data}

The Israeli local authority structure includes three types of local authorities: (a) a municipality (city) - an urban community (a city) usually with a population of 20,000 or more residents; (b) a local council - a small city (normally fewer than 20,000 residents) that developed over time from one large rural community or several small, geographically related, rural communities; and (c) a regional council - the governing body of several, possibly many, rural communities that are located within a given geographical region. Our targeted research population consisted of 263 local authorities in Israel: 62 municipalities, 148 local councils, and 53 regional councils.

After completing a pre-test (see description above), a questionnaire with a self-addressed reply envelope was mailed from a university address to the general management of each local authority in Israel. Ninety-nine of the 106 questionnaires (38\%) that were completed and returned to us were usable, that is, they included all the necessary data. The response rate across the three different types of local authorities was about equal: that is, of the 99 usable questionnaires 24 were from municipalities (cities), 56 from local councils, and 19 from regional councils. This is similar to the distribution of the population of local authorities in Israel.

The variables that we used in this study were obtained from several sources. Measures of financial performance, geographical location, and municipal development were obtained from a Ministry of Interior (1999) report and the annual financial reports of the local authorities for 1997 and 1998. Variables representing the local authority's organizational size were extracted from Publication 1046
(Local authorities in Israel 1995: Physical data 1997) of the Israel Central Bureau of Statistics, as well as from internal reports of the Ministry of Interior. Data on the employment rate were obtained from the Social Science Data Archive (SSDA) of the Hebrew University of Jerusalem. Finally, the data that were used to develop the measures of the local authority's organizational elements, and the data representing perceived environmental uncertainty, were obtained from the questionnaire. $^{3}$

\section{Measures}

This study investigates the effect of organizational elements, perceived environmental uncertainty, geographical location, and organization size (the independent variables) on a set of performance measures of the local authority (the dependent variables).

\section{Dependent variables}

\section{Financial performance}

Two measures are used to represent the fiscal strength of the local authority (see Carmeli, 2002): self-income ratio and collecting efficiency ratio.

Self-income ratio is the proportion of selfincome in the local authority's overall income as reported in its regular budget. Self-income consists of all the income (taxes, grants, and fees) that the local authority collects directly from its residents, businesses, and other assets within its jurisdiction. Overall income in the regular budget consists of property taxes, fees, surcharges, general grants, financing from ministries, and single sources of income. The closer the self-income ratio to unity, the greater is the fiscal strength (health) of the local authority.

Collecting efficiency ratio is the proportion of the current year's actual collecting (the total amount of income that was collected by the local authority) in the total income theoretically collectable during the current year. Actual collecting

\footnotetext{
${ }^{3}$ This design raises some concerns about the probability that the respondents are biased in estimating the elements of their organization. To circumvent this problem, or at least diminish it, we asked the respondents (general managers) to refer to the entire organization, rather than themselves. A second concern with the data collected by questionnaires is whether the respondents possess sufficient knowledge to accurately assess organizational elements. Previous studies indicate that top managers are a reliable source of information (O'Reilly, Snyder, and Boothe, 1993; Miller, Burke, and Glick, 1998).
} 
consists of property taxes, water, and sewage fees. The total income to be collected consists of accumulated debt from earlier years, the current year's 'income to be collected' minus discounts and cancellation of self-income.

Employment rate is one of the most important performance measures by which a local authority in Israel is evaluated. It is defined as the ratio of the number of permanent residents net of the number of job seekers (monthly average), to the number of permanent residents. The total number of permanent residents consists of all the permanent residents and migrants in Israel, including the permanent residents who were away from Israel for less than 1 year during the survey that collected the data for this measure (Israel Central Bureau of Statistics, 1997: 19). It should be noted in this context that local authorities strive to reduce the level of unemployment by creating business zones and attracting new enterprises (by providing them with special incentives).

Municipal development consists of two ratios: development expenditure ratio and local services' expenditure ratio. Development expenditure ratio is the ratio between the total amount of expenses aimed at local development, and the number of permanent residents. Local services' expenditure ratio is the ratio between the budget expenditures on services, and the number of permanent residents. Cronbach's alpha of this measure is 0.87 . It should be noted in this context that the local authority better serves its goals by allocating its resources directly to the various municipal services.

Internal migration is the ratio between the number of permanent residents at the end of the current and previous year. A strong local authority is likely to exhibit an increase in its permanent population.

\section{Independent variables}

The independent variables are divided into two groups: (a) organizational elements and (b) all other variables (denoted control variables) that may influence performance. We first describe the organizational elements.

\section{Organizational elements}

Six intangible organizational elements obtained from the local authorities' general managers are used in this study. Scores are on a 7-point scale ranging from $1=$ strongly disagree to $7=$ strongly agree. The six measures are defined as follows and their items are detailed in Appendix 1.

Managerial capabilities is an adaptation of the measure developed by Hitt and Ireland (1985). It consists of 12 items such as 'attracting and retaining well-trained and competent top managers,' and 'ability to unify conflicting opinions, improve coordination and enhance effective collaboration between key executives, generate enthusiasm, and motivate sufficient managerial drive for better performance'. Cronbach's alpha of this measure is 0.88 .

Human capital has three dimensions: education, work experience, and competence of the firm's members (Aryee, Chay, and Tan, 1994). The respondents were asked to evaluate four items relating to education and work experience, and eight items relating to competence (Wagner and Morse, 1975). Sample items are 'in my local authority, employees have suitable education to fulfill their jobs,' and 'in my local authority, employees are well trained.' Cronbach's alpha for this measure is 0.80 .

Internal auditing is based on the model developed by Eden and Moriah (1996). It consists of seven items that cover four aspects of the auditing system: teaching, motivating, deterrence, and process improvement. Sample items are 'the internal auditing prevents inappropriate actions which may harm the organization,' and 'the internal auditing is perceived as a threat to the position and status of the employees' (a reverse-scored item). Cronbach's alpha for this measure is 0.89 .

Labor relations are measured by a development of the model presented by Kitay and Marchington (1996) consisting of nine items. The measure covers the degree of trust and satisfaction in the relations between the management and employees, the degree to which the labor relations are planned and managed, and the extent to which the labor relations system pursues the principles of safety, fairness, individualism, and democracy. Sample items are 'there is complete trust between the management and employees,' and 'there are mutual respect and good intentions between the management and employees.' Cronbach's alpha for this scale is 0.93 .

Organizational culture is based on Denison's (1990) model with its four hypotheses. (1) The involvement hypothesis: organizational effectiveness is a function of the level of involvement and participation of the organization's members. 
(2) The consistency hypothesis: organizational effectiveness is a function of the degree to which the organization's members understand and hold a shared system of beliefs, values, and symbols. (3) The adaptability hypothesis: organizational effectiveness is a function of the organization's ability to perceive the external and internal environment and respond to it through reinstitutionalization of a set of behaviors and processes. (4) The mission hypothesis: organizational effectiveness is a function of the degree to which the organization's members hold a shared definition of the function and purpose of the organization and its members. A mission enhances employees' connection with the organization and provides direction and goals that serve to define the appropriate course of action for the organization and its members. Eight items (phrases/questions) represent the four ingredients of the model. Sample items are 'all have a common set of values, creeds, and symbols,' and 'there is high involvement of the employees in the processes, decisions, and their implementation.' Cronbach's alpha for this measure is 0.81 .

Perceived organizational reputation is an integration of two measures established by a city reputation survey (see Bromley, 1993) and the reputation survey of Fortune magazine, adapted to the unique function of the local authorities in Israel. The first measure is derived from items in a survey among 600 managers and experts regarding the reputation of U.S. cities (see Bromley, 1993). It consists of items such as: flexible and high-quality manpower; accessibility to markets; favorable attitude toward businesses; fine public education system; comfortable flying service to major cities; low cost of housing; jobs; facilities; taxes; and quality of life. The other measure is derived from Fortune's annual corporate reputation survey among 8000 high-ranking executives, outside directors and financial analysts, who were asked to rate the 10 largest companies in their own industry on eight attributes, using a scale of 0 (poor) to 10 (excellent). The attributes were: quality of management; quality of products or services; innovativeness; long-term investment value; financial soundness; ability to attract, develop and keep talented people; community and environmental responsibility; and use of corporate assets (see, for example, Smith, Fortune, January 29, 1990). This measure has been used by numerous scholars, including Fombrun and Shanley (1990), Fryxell and Wang (1994), Gatewood, Gowan, and Lautenschlager (1993), and McGuire, Sundgren, and Schneeweiss (1988).

To preserve the general definition of perceived organizational reputation while integrating into it the unique characteristics of a public sector organization (a local authority in our case), we use here a measure that consists of four items based on the corporate reputation survey, and five items that are based on the city reputation survey. Sample items are 'the ability of my local authority to attract, develop, and keep talented people is rated very favorably,' and 'in my local authority, the municipal facilities are credited with a very favorable reputation.' Cronbach's alpha for this measure is 0.82 .

\section{Control variables}

The variability of performance across heterogeneous organizations may be due, in addition to organizational elements, to various other effects that may represent the unique nature of particular organizations and the environment in which they operate. Three variables - perceived environmental uncertainty, organizational (community) size, and location - are used in this study to control for these effects across the local government authorities in Israel.

Perceived environmental uncertainty is defined here as the perception of the organization's top management regarding its ability, or inability, to decide and direct the future of its task environment. Israel's local government has faced many challenges over the last two decades, one of the most important being the increased interest of the constituencies in the way the local authority is managed. Whereas 20 years ago the country's political parties dominated the process of electing the local authority head, whose primary obligation was to the party, growing public awareness, brought about in part by increased media coverage, has made the local authority elections far more open and competitive. The result is that residents now expect their local authorities to be well managed, accountable, and responsible for job creation by attracting businesses and investors. Clearly, the current environment in which the local authorities operate has become more uncertain, which may be an important factor influencing organizational performance.

The theoretical background for our measure of perceived environmental uncertainty derives from 
Dess and Beard's (1984: 64) suggestion that an environmental classification would provide useful building blocks to improve the conceptualization and measurement of organizational task environments. It also reflects the view that in an uncertain competitive environment the organization may experience difficulties in understanding what its future direction will be (see Milliken, 1987).

The measure of perceived environmental uncertainty that we employ here was developed by Miller and Droge (1986) and has been used in many organizational research studies (e.g., Waldman et al., 2001). The measure consists of five items, including 'my local authority rarely has to change its customer practices to keep up with other local authorities,' and 'actions of other local authorities are quite easy to predict.' Cronbach's alpha for this measure is 0.64 .

Organizational (community) size, defined as the number of permanent residents in a particular jurisdiction, may affect the performance of a local authority. Though a large local authority may presumably enjoy economies of scale, a recent study by Martins (1995) shows that it is difficult to determine an optimal size. Furthermore, large local authorities tend to be over-bureaucratic and, hence, may find it difficult to successfully fulfill their duties (Leach, Stewart, and Walsh, 1994). Be that as it may, local authority size is represented by the number of its permanent residents.

Location may also play a significant role in the success of a local authority. The local authorities in Israel are classified into three geographical locations: south, center, and north. Each of these locations is represented by a dummy variable. Local authorities in the center of the country, where the majority of the population resides, enjoy significant resources from the central government, with Tel Aviv clearly Israel's business and financial hub. Local authorities from the north and south have long been arguing against the ongoing discrimination against their communities. Thus, we expect local authorities at the center to exhibit better organizational performance than those in the north and south.

\section{The multivariate analysis approach}

Multivariate analysis is often employed when researchers need to represent a very large data set by several, easy-to-interpret variables or when it is necessary to relate one set of variables to other sets of variables. This method facilitates the identification of the effects of key variables in one data set on all or several of the variables in other sets.

There are several types of multivariate analysis. In the case of two or more data sets, canonical correlation analysis (CCA) has been successfully used in different applications in the behavioral, social and economic sciences (Cliff, 1987; Dillon and Goldstein, 1984; Timm, 1975; Tishler et al., 1996). However, when the number of variables in one of the data sets is large (relative to the number of observations), which is often the case in studies in the area of management, the weights obtained by CCA (and regression analysis) are usually extremely unreliable due to multicollinearity among the variables (Judge et al., 1985; Tishler and Lipovetsky, 2000).

To circumvent the multicollinearity problem and obtain reliable and robust weights, Tishler and Lipovetsky (2000) developed and applied the method of robust canonical analysis (RCA), which has been used successfully in management applications (Ahituv, Lipovetsky, and Tishler, 1999; Azulay, Lerner, and Tishler, 2002; Tishler et al., 1996).

Applying the RCA method to two data sets amounts to estimating the weights which maximize the covariance between linear aggregators (weighted averages) of the two data sets. RCA is applied to standardized variables. Thus, although formal statistical inference of the RCA estimates is unavailable (as is the case with other multivariate canonical correlation methods; see Cliff, 1987; Dillon and Goldstein, 1984), a variable with a large estimated weight affects the connection between the two data sets more than a variable with a small weight. Variables in one data set are defined as critical (important) relative to those in the second data set when their weights in the RCA between the two data sets are large (see Tishler et al., 1996; Tishler and Lipovetsky, 2000) for algorithms that select critical variables from large data sets. Variables that are not designated as critical relative to the other data set may still affect this set. However, their influence on the second data set may not be as pronounced as the influence of critical variables.

Finally, the statistic $q^{2}$, which measures the share of the explained variability out of the total variability among the correlations of the variables in the two data sets, is equivalent to the wellknown $R^{2}$ in a regression model. The squared 
canonical correlation among the critical variables, $r_{C C}^{2}$, which, like forecasting with the RCA method, uses all the correlations among the critical variables and is also an important measure of goodness of fit of the final RCA model (see Tishler and Lipovetsky, 2000; Tam, 2003). ${ }^{4}$

\section{RESULTS}

The means, standard deviations, and correlations among the research variables are presented in Table 1. The correlations between each organizational element and the control variables or variables representing performance are relatively low, as are the correlations among the variables representing performance and between these variables and the control variables. Most of the correlations among organizational elements are, however, rather large, which is only to be expected since organizations being aware of the importance of most of their organizational elements to their performance tend to balance their values. The high correlations, however, mean that we cannot use multiple regression analysis or CCA, which are prone to multicollinearity, in assessing the effect on organizational performance of organizational elements, let alone the interactions among them. The RCA procedure provides estimates that are robust and more reliable than multiple regression or CCA when multicollinearity among the variables is severe (see Tishler and Lipovetsky, 2000; Tam, 2003). Hence, the effects of the six intangible organizational elements and their interactions on the performance of the local authorities in Israel were estimated by RCA. Table 2 reports the effect of the control variables on organizational performance. Table 3 reports the effect of the control variables and the intangible organizational elements on organizational performance. Table 4 presents the effect of the control variables, the intangible organizational elements (the 'main effects'), and the interactions among the intangible organizational elements on organizational performance.

The results in Tables 2-4 lend support to Hypotheses 1 and 2. That is, intangible organizational elements and their interactions have a positive

\footnotetext{
${ }^{4}$ A brief formal presentation of the RCA method and the goodness-of-fit measures are in Appendix 2.

effect on organizational performance. The goodness of fit is $q^{2}=0.71$ when organizational performance is explained only by the control variables. It increases to $q^{2}=0.85$ when intangible organizational elements are added to the model, and further increases to $q^{2}=0.93$ when organizational performance is explained by the interactions of the intangible organizational elements in addition to the control variables and the intangible organizational elements. The results in Table 4, the full model, are discussed below.

The intangible organizational elements that we use here are positively related to all the organizational performance measures, except for internal migration. Thus, the results in Table 4 provide strong support for the postulate of Hypothesis 1 that intangible organizational elements are positively associated with organizational performance. We find that organizational culture and perceived organizational reputation are the measures most important to organizational performance (with coefficients of 0.24 and 0.23 , respectively), while the other four intangible organizational elements exhibit a similar degree of importance, as do perceived environmental uncertainty and geographical location (with absolute values of the estimated coefficients at or somewhat below $0.20)$. This clearly indicates that organizations with strong organizational culture and favorable perceived organizational reputation achieve abovenormal performance, and that high measures of labor relations, human capital, internal auditing, and managerial capabilities are also critical to organizational performance.

The estimates in Table 4 also lend strong support to Hypothesis 2. All the coefficient estimates of the 15 interactions among the six organizational elements are positive and substantial in size, showing that the effect of any given organizational element on the organization's performance is larger, the larger are the effects of the other organizational elements. That is, organizational elements enhance each other in their effect on the performance of the sample local authorities. As is the case with the direct effects of organizational elements on organizational performance, the effects of the interactions of organizational culture and perceived organizational reputation with the other organizational elements are somewhat larger (i.e., more important in their effect on organizational performance) than the effects of the interactions with the remaining four organizational elements.

Strat. Mgmt. J., 25: 1257-1278 (2004) 


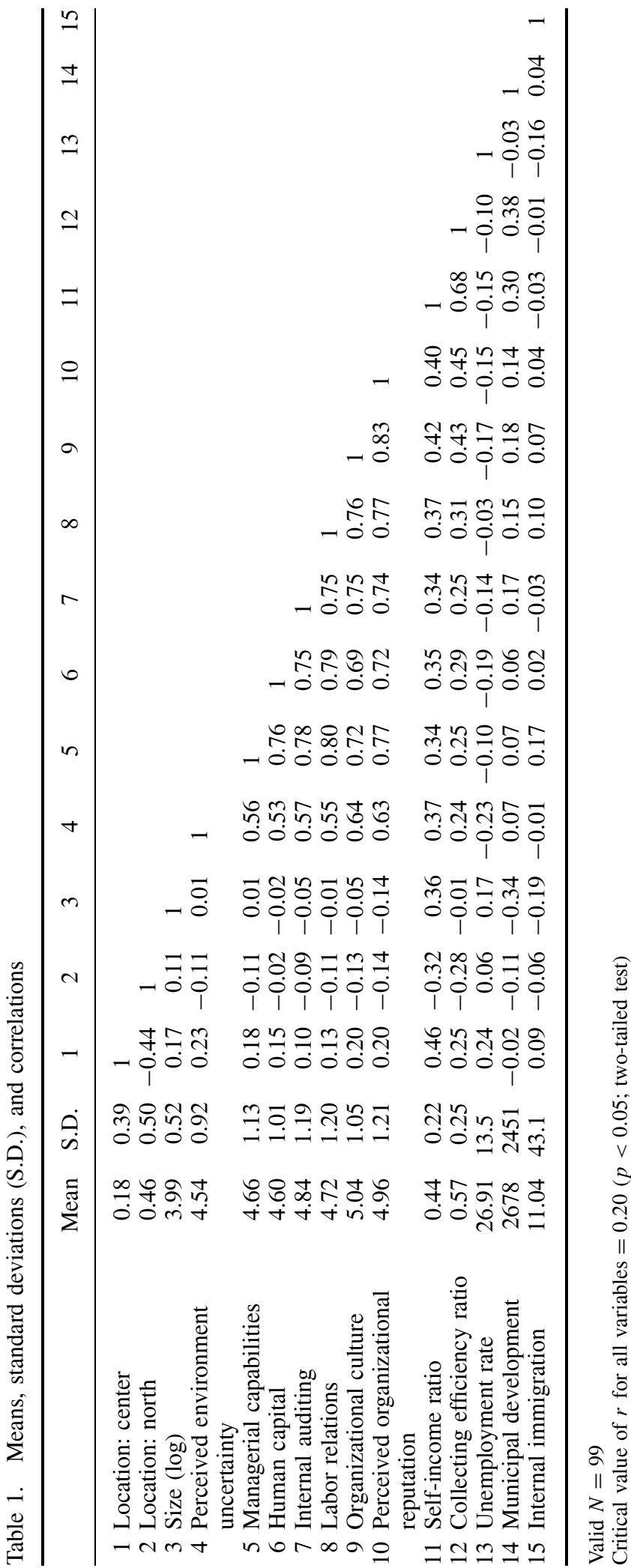


Table 2. The effects of location, size and environmental uncertainty on organizational performance $^{\mathrm{a}}$

\begin{tabular}{lrlr}
\hline Performance Measures & Weight & Control and Independent Variables & Weight \\
\hline Self-income ratio & 0.83 & Location: center & 0.47 \\
Collecting efficiency ratio & 0.47 & Location: north & -0.64 \\
Employment rate & 0.29 & Organizational size (LOG) & -0.29 \\
Municipal development & -0.03 & Perceived environmental uncertainty & -0.54 \\
Internal migration & 0.02 & & \\
\hline
\end{tabular}

${ }^{\mathrm{a}} q^{2}=0.71 ; r_{C C}^{2}=0.55$

Table 3. The effects of the control variables and the organizational elements on organizational performance $^{\mathrm{a}}$

\begin{tabular}{lclr}
\hline Performance measures & Weight & Control and independent variables & Weight \\
\hline Self-income ratio & 0.73 & Location: center & 0.35 \\
Collecting efficiency ratio & 0.59 & Location: north & -0.27 \\
Employment rate & 0.27 & Organizational size (LOG) & 0.09 \\
Municipal development & 0.16 & Perceived environmental uncertainty & -0.31 \\
Internal migration & 0.04 & Managerial capabilities (MC) & 0.28 \\
& & Human capital & 0.31 \\
& & Internal auditing & 0.29 \\
& & Labor relations & 0.31 \\
& & Organizational culture & 0.41 \\
& & Perceived organizational reputation & 0.40 \\
\hline
\end{tabular}

$$
{ }^{\mathrm{a}} q^{2}=0.85 ; r_{C C}^{2}=0.60
$$

Table 4 also indicates that four performance measures (self-income ratio, collecting efficiency ratio, employment rate, and municipal development) can be well explained by the six intangible elements and the interactions among them, together with variables representing the perceived environmental uncertainty and location of the local authority. The squared canonical correlation between the weighted average of the independent variables - intangible organizational elements and the interactions among them, as well as the other control variables, and the weighted average of the variables representing organizational performance-is 0.71 . The estimates in Table 4 also indicate that the 'financial performance' measures, represented by self-income ratio and collecting efficiency ratio, are by far the most important to the local authority's overall organizational performance. The local authority's employment rate and its municipal development, while of importance in forming the measure of overall organizational performance, are less critical than the financial performance measures.

Finally, the estimates in Table 4 indicate that geographical location and perceived environmental uncertainty are important factors in explaining the variability in the performance of local authorities in Israel, but organizational size (whether measured in absolute value or in logarithms) is not. Perceived environmental uncertainty was related negatively to all four measures of performance. It seems that organizations that perceive their environment as highly uncertain are more likely to show below-normal performance than those that perceive the task environment as more certain. Location is also critically associated with organizational performance. That is, local authorities in the central part of Israel outperform local authorities in the north and in the south.

\section{DISCUSSION AND CONCLUSIONS}

Today, perhaps more than in the past, managers, whether in the business or public sector, are finding it difficult to cope with the increasingly uncertain environment and are therefore coming to the realization that the rules have changed and they now need to compete on strategic elements in order to outperform their rivals (Prahalad and Hamel, 
Table 4. The effects of the organizational elements and their interactions on organizational performance ${ }^{\mathrm{a}}$

\begin{tabular}{|c|c|c|c|}
\hline Performance measures & Weight & Control and independent variables & Weight \\
\hline Self-income ratio & 0.73 & Location: center & 0.20 \\
\hline Collecting efficiency ratio & 0.60 & Location: north & -0.16 \\
\hline Employment rate & 0.24 & Organizational size (LOG) & 0.05 \\
\hline Municipal development & 0.20 & Perceived environmental uncertainty & -0.18 \\
\hline \multirow[t]{21}{*}{ Internal migration } & 0.02 & Managerial capabilities (MC) & 0.16 \\
\hline & & Human capital & 0.18 \\
\hline & & Internal auditing & 0.17 \\
\hline & & Labor relations & 0.18 \\
\hline & & Organizational culture & 0.24 \\
\hline & & Perceived organizational reputation & 0.23 \\
\hline & & Managerial capabilities $\times$ Human capital & 0.18 \\
\hline & & Managerial capabilities $\times$ Internal auditing & 0.18 \\
\hline & & Managerial capabilities $\times$ Labor relations & 0.18 \\
\hline & & Managerial capabilities $\times$ Org. culture & 0.21 \\
\hline & & Managerial capabilities $\times$ Reputation $^{\mathrm{b}}$ & 0.21 \\
\hline & & Human capital $\times$ Internal auditing & 0.19 \\
\hline & & Human capital $\times$ Labor relations & 0.19 \\
\hline & & Human capital $\times$ Org. culture & 0.23 \\
\hline & & Human capital $\times$ Reputation & 0.23 \\
\hline & & Internal auditing $\times$ Labor relations & 0.19 \\
\hline & & Internal auditing $\times$ Org. culture & 0.21 \\
\hline & & Internal auditing $\times$ Reputation & 0.22 \\
\hline & & Labor relations $\times$ Org. culture & 0.22 \\
\hline & & Labor relations $\times$ Reputation & 0.22 \\
\hline & & Org. culture $\times$ Reputation & 0.25 \\
\hline
\end{tabular}

\footnotetext{
${ }^{a}$ This model consists of all the control and independent variables and interactions that are discussed in the research.

b 'Reputation' stands for 'Perceived organizational reputation'.

$q^{2}=0.93 ; r_{C C}^{2}=0.71$
}

1990). In this public sector study of local authorities in Israel, we focus on a set of six intangible elements and their direct and interactive effects on a set of five organizational performance measures, while controlling for the effects of location, perceived environmental uncertainty, and organizational (community) size. Using multivariate analysis, we demonstrate that intangible elements, together with environmental uncertainty and geographical location, strongly affect the performance of local authorities.

We adopt the argument that the resource-based view (RBV) can serve as a useful paradigm for the analysis of variations in the performance of public sector organizations, designing the study to overcome some of the difficulties that RBV researchers have been facing. In so doing, we contribute to filling the gap in the literature on the applicability of the RBV to the public and not-for-profit sector. Second, following Robins and Wiersema
(1995), we adopt a behavioral approach to operationalize and measure the strategic characteristics of organizations as identified by the RBV. Third, this study does not limit itself to the analysis of one resource (or capability) on the performance of the organization. Rather, it analyzes the simultaneous effect of a set of organizational elements on organization performance (as do, for example, Hitt and Ireland, 1985). Thus, we emphasize that no organization is likely to outperform its rivals based on a single strategic resource. Fourth, this study uses measures that capture the multidimensionality of organizational performance. Clearly, neither business firms nor local authorities can be evaluated solely on the basis of their financial performance. Public organizations in particular are also judged on their social performance (such as contribution to the community and environmental responsibility). Also, as noted above, local authorities are now responsible for activities that they 
had not been concerned with in the past, such as job creation.

The estimation results demonstrate several important effects of intangible elements on the performance of local authorities. First, it is clearly shown that intangible elements are critical for an organization to attain its goals and accomplish above-normal performance, organizational culture and perceived organizational reputation appearing to be far more important than the other intangible resources. The finding that strong organizational culture is critical to a local authority in achieving an advantageous position is especially notable, since it generalizes previous theoretical propositions on its importance for business organizations (see Barney, 1986). A local authority with a strong organizational culture that emphasizes elements such as high involvement of the organization's members, shared beliefs, ability to adapt to the environment, and a sense of mission (Denison, 1990) is likely to perform better than its counterparts lacking such an organizational culture. The finding that perceived organizational reputation is also a highly critical resource is consistent with the theory as well as empirical findings of previous research (see Fombrun, 1996; Roberts and Dowling, 2002; Shrum and Wuthnow, 1988). As in the business sector, local authorities exploit a favorable reputation that cannot be easily imitated by competitors to achieve superior performance. Highly reputable local authorities can, for example, attract new residents from the higher socioeconomic levels, as well as new investors, and thus strengthen their fiscal state, create new jobs, and offer a higher standard of living.

Labor relations, human capital, internal auditing, and managerial capabilities are also important in achieving above-normal organizational performance. Good labor relations between the management and the employees are likely to improve the performance of a local authority. The results indicate that upholding principles such as fairness, safety, and trust is likely to motivate members to higher production and overall standards, thereby countervailing the effects of inefficiency, ineffectiveness, and concealed unemployment that too often burden local authorities in Israel. The implication is that organizations with good labor relations will manage to retain the rent generated rather than enabling the employees to appropriate large portions of it. Clearly, managers should take care to ensure that the rent generated by positive labor relations is not offset by costs associated with the establishment and maintenance of these labor relations (see Coff, 1999). Human capital is also found to be a source of higher performance by local authorities. It seems that local authorities implementing strategic human resource management practices that result in organization-specific educated and trained employees outperform those that do not implement such practices (Huselid, 1995; Huselid, Jackson, and Schuler, 1997), which strengthens the premise that people are a valuable organizational resource (Collis and Montgomery, 1998; O'Reilly and Pfeffer, 2000; Pfeffer, 1994). Internal auditing is also a critical resource for the local authority, apparently helping the employees to focus on doing the right things and doing them right, through teaching, motivating, deterrence, and process improvement (Eden and Moriah, 1996). It may also be an important aid to local authorities in the proper management of their complex organizations, leaving them less open to accusations of mismanagement. The estimation results show that managerial capabilities are also important for the success (high performance) of a local authority. These findings are consistent with the importance that business organizations attribute to their top management and the capabilities they possess in generating rent for the firm (Castanias and Helfat, 1991; Hambrick and Mason, 1984; Finkelstein and Hambrick, 1996; Mahoney, 1995; Yukl, 1981).

One of the most important findings of this study is that organizational elements enhance each other in their effect on organizational performance. That is, the 'marginal productivity' of each organizational element is higher the higher are the values of all other organizational elements. This result suggests that local authorities seeking to maximize their performance subject to a given budget should balance the development of their organizational elements. Though optimal values of various organizational elements may differ due to the different cost entailed in developing each of them, our results indicate that local authorities should attempt to estimate not only the direct effect of each organizational element on performance, but also assess the effects on performance of the interactions among them.

Perceived environmental uncertainty is negatively related to organizational performance. That is, the more uncertain the environment is perceived to be, the lower the performance of the local 
authority. It seems that organizations that outperform their competitors better analyze and understand their task environment and are thus more adaptable. Their superior understanding of the current and future environmental trends makes them better able to fit into the ever-changing environment.

As to geographical location, local authorities located in central Israel perform better in a variety of functions than those located in the north and south of the country. This outcome is due mainly to the concentration of business and government activities in the center of Israel.

In conclusion, the observation made by Collis and Montgomery (1998: 27) that resources are 'the substance of strategy, the very essence of sustainable competitive advantage' finds support in our study, as does the argument that gaining and preserving superiority in competitive environments rests on a set of strategic elements (Amit and Schoemaker, 1993; Barney, 1991; Wernerfelt, 1984). The design of this study may also contribute to overcoming some difficulties in quantitative analyses in the field and extend the use of the RBV to the public sector.

\section{Limitations and suggestions for future research}

Two limitations of the study need elaboration: causality and generalizability. It seems important to inquire whether the performance of local government authorities is driven mainly by intangible elements and not by other, possibly unobserved, variables. Clearly, this is possible. Though we have made a substantial effort to explain the importance of intangible elements in a service and knowledge society, more research is needed to extend the set of intangible resources, and simultaneously estimate the effect of tangible and intangible resources on organizational performance. Another issue concerning causality is the large number of functions that the local authority is expected to carry out. A study of the performance of these organizations may have to explore all the activities for which they are accountable. This study employs objective data on several performance measures of the local authorities in order to capture the multidimensionality of their performance. Further research is needed to extend the measures that relevant stakeholders use to evaluate the performance of public organizations such as local authorities.
The second concern is the generalizability of the study, which may be limited due to the uniqueness of the local government task environment (Dess, Ireland, and Hitt, 1990: 13). It was precisely the fact that local government in Israel can be viewed as a definable task environment (i.e., a single industry) that allowed us to apply the RBV, with its primary interest on competitive advantage, which, by definition, is task-environment specific. Moreover, the elements of local government that are the focus of this study are task-environment specific and cannot be easily transferred across environment boundaries. Also, by studying a single task environment, the researcher eliminates the need to measure and control for a broad range of environment-specific factors. Nevertheless, despite the obvious need to exercise cautious in generalizing the results of applying the RBV in a single-task environment to other environments, we are confident that the findings of this study can, with some modifications, be applied to other settings. For example, a strong organizational culture has been found to play a significant role in business and public organizations alike. Thus, the issue is how, not whether, to match the competitive strategy and the culture of the organization (Itami with Roehl, 1987). We believe that an interesting avenue of research would be to compare the effect of intangible elements on organizational performance across the private and the public sectors.

\section{Conclusion}

In this article we have made an attempt to advance the research on complementarities from anecdotal and case study evidence to a relatively largesample study. We estimated the influence of a set of intangible elements and their interactions on a set of performance measures in a public sector setting. Our results, in general, indicate the value of intangible elements (resources) and their mutually enhancing interactions for organizational performance. However, the task of coordinating and balancing the development of organizational elements, within investment constraints, in the effort to maximize performance is quite complex (cf. Rivkin, 2000; Siggelkow, 2002). To practically resolve this complexity, it may be beneficial to disaggregate the organization into discrete elements, as in Porter's (1985) value chain, and examine the value of each element independently and interactively with one or more elements. Though this may 
seem at first sight to be a mission beyond the organization's capability, we believe that senior managers have the knowledge and circumspection to provide relatively accurate observations regarding the core and non-core elements and the interactions among them that ultimately constitute the overall value of the organization. Finally, the notion of complementarities is especially important given the findings of previous studies (e.g., Barnett and Freeman, 2001) that too much emphasis on a particular good element may produce a negative effect by creating an imbalance among the individual elements and within the system as a whole. We extend this insight by discouraging managers from placing too much emphasis on a particular set of interactions, encouraging them rather to create a balance in such a way that the whole is greater than the sum of its parts (see Makadok, 2003).

\section{ACKNOWLEDGEMENTS}

We wish to thank Aaron Cohen, Associate Editor Will Mitchell, and two anonymous reviewers for their insightful comments and suggestions. We also thank the participants of the research seminar in the Department of Management at Drexel University for their comments on an earlier draft of this paper.

\section{REFERENCES}

Ahituv N, Lipovetsky S, Tishler A. 1999. The relationship between firm's information systems policy and business performance: a multivariate approach. In Measuring Information Technology Investment Payoff: Contemporary Approach, Mahmood MA, Szewizak EJ (eds). Idea Group: Hershey, PA; 62-82.

Amit R, Schoemaker PJH. 1993. Strategic assets and organizational rent. Strategic Management Journal 14(1): 33-46.

Aryee S, Chay YW, Tan HH. 1994. An examination of the antecedents of subjective career success among a managerial sample in Singapore. Human Relations 47(5): 487-509.

Asefa S, Huang WC (eds). 1994. Human Capital and Economic Development. W. E. Upjohn Institute for Employment Research: Kalamazoo, MI.

Azulay I, Lerner M, Tishler A. 2002. Converting military technology through corporate entrepreneurship. Research Policy 31: 419-435.

Barnett WP, Freeman J. 2001. Too much of a good thing? Product proliferation and organizational failure. Organization Science 12(5): 539-558.

Barney JB. 1986. Organizational culture: can it be a source of sustained competitive advantage? Academy of Management Review 11(3): 656-665.
Barney JB. 1991. Firm resources and sustained competitive advantage. Journal of Management 17(1): 99-120.

Barney JB. 2001. Is the resource-based 'view' a useful perspective for strategic management research? Yes. Academy of Management Review 26(1): 41-56.

Becker GS. 1993. Human Capital: A Theoretical and Empirical Analysis, with Special Reference to Education (3rd edn). University of Chicago Press: Chicago, IL/National Bureau of Economic Research: New York.

Boxall P, Steeneveld M. 1999. Human resource strategy and competitive advantage: a longitudinal study of engineering consultancies. Journal of Management Studies 36(4): 443-463.

Bromley DB. 1993. Reputation, Image and Impression Management. Wiley: Chichester.

Canals J. 2000. Managing Corporate Growth. Oxford University Press: New York.

Carmeli A. 2002. A conceptual and practical framework of measuring performance of local authorities in financial terms: analysing the case of Israel. Local Government Studies 28(1): 21-36.

Castanias RP, Helfat CE. 1991. Managerial resources and rents. Journal of Management 17(1): 155-171.

Chatterjee S, Wernerfelt B. 1991. The link between resources and type of diversification: theory and evidence. Strategic Management Journal 12(1): 33-48.

Cliff N. 1987. Analyzing Multivariate Data. Harcourt Brace Jovanovich: San Diego, CA.

Coff RW. 1999. When competitive advantage doesn't lead to performance: the resource-based view and stakeholder bargaining power. Organization Science 10(2): 119-133.

Collis DJ, Montgomery CA. 1998. Corporate Strategy: A Resource-Based View. Irwin/McGraw-Hill: Boston, MA.

Dastmalchian A, Blyton P, Adamson R. 1991. The Climate of Workplace Relations. Routledge: London.

Denison DR. 1990. Corporate Culture and Organizational Effectiveness. Wiley: New York.

Dess GG, Beard DW. 1984. Dimensions of organizational task environments. Administrative Science Quarterly 29: 52-73.

Dess GG, Ireland RD, Hitt MA. 1990. Industry effects and strategic management research. Journal of Management 16(1): 7-27.

Dillon WR, Goldstein M. 1984. Multivariate Analysis, Methods and Applications. Wiley: New York.

Dutton JE, Dukerich JM, Harquail CV. 1994. Organizational images and member identification. Administrative Science Quarterly 39(2): 239-263.

Eden D, Moriah L. 1996. Impact of internal auditing on branch bank performance: a field experiment. Organizational Behavior and Human Decision Processes 68(3): 262-271.

Farjoun M. 1994. Beyond industry boundaries: human expertise, diversification and resource-related industry groups. Organization Science 5: 185-199. 
Finkelstein S, Hambrick D. 1996. Strategic Leadership: Top Executives and their Effects on Organizations. West: St Paul, MN.

Fombrun CJ. 1996. Reputation: Realizing Value from the Corporate Image. Harvard Business School Press: Boston, MA.

Fombrun CJ, Shanley M. 1990. What's in a name? Reputation building and corporate strategy. Academy of Management Journal 33(2): 233-258.

Fryxell GE, Wang J. 1994. The Fortune corporate 'reputation' index: reputation for what? Journal of Management 20(1): 1-14.

Gatewood RD, Gowan MA, Lautenschlager GJ. 1993. Corporate image, recruitment image, and initial job choice decisions. Academy of Management Journal 36(2): 414-427.

Globerson A, Globerson S. 1990. Control and Evaluation in Organizations: Management by Measurement. Tel Aviv University: Tel Aviv, Israel.

Godfrey PC, Hill CWL. 1995. The problem of unobservables in strategic management research. Strategic Management Journal 16(7): 519-533.

Hambrick DC, Mason PA. 1984. Upper echelons: the organization as a reflection of its top management. Academy of Management Review 9: 193-206.

Hershberg T. 1996. Human capital development: America's greatest challenge. Annals of the American Academy of Political Science 544(March): 43-51.

Hitt MA, Ireland RD. 1985. Corporate distinctive competence, strategy, industry and performance. Strategic Management Journal 6(3): 273-293.

Hitt MA, Bierman L, Shimizu K, Kochhar R. 2001. Direct and moderating effects of human capital on strategy and performance in professional service firms: a resource-based perspective. Academy of Management Journal 44(1): 13-28.

Hoskisson RR, Hitt MA, Wan WP, Yiu D. 1999. Theory and research in strategic management: swings of a pendulum. Journal of Management 25(3): 417-456.

Huselid MA. 1995. The impact of human resource management practices on turnover, productivity, and corporate financial performance. Academy of Management Journal 38(3): 635-672.

Huselid MA, Jackson SE, Schuler RS. 1997. Technical and strategic human resource management effectiveness as determinants of firm performance. Academy of Management Journal 40(1): 171-188.

Israel, Central Bureau of Statistics. 1997. Local Authorities in Israel 1995: Physical Data (Publication 1046). Central Bureau of Statistics: Jerusalem.

Itami H, Roehl WT. 1987. Mobilizing Invisible Assets. Harvard University Press: Cambridge, MA.

Javidan M. 1998. Core competence: what does it mean in practice? Long Range Planning 31(1): 60-71.

Judge GG, Griffiths WE, Hill RC, Lütkepohl H, Lee TC. 1985. The Theory and Practice of Econometrics (2nd edn). Wiley: New York.

Katz RL. 1974. Skills of an effective administrator. Harvard Business Review 52(5): 90-102.

Kitay J, Marchington M. 1996. Review and critique of workplace industrial relations typologies. Human Relations 49(10): 1263-1290.
Klein AS, Masi RJ, Weidner II CK. 1995. Organization culture, distribution and amount of control, and perceptions of quality: an empirical study of linkages. Group and Organization Management 20(2): $122-148$

Lado AA, Wilson MC. 1994. Human resource systems and sustained competitive advantage: a competencybased perspective. Academy of Management Review 19(4): 699-727.

Leach S, Stewart J, Walsh K. 1994. The Changing Organisation and Management of Local Government . Macmillan Press: London.

Leonard-Barton D. 1992. Core capabilities and core rigidities: a paradox in managing new product development. Strategic Management Journal, Summer Special Issue 13: 111-125.

Mahoney JT. 1995. The management of resources and the resources of management. Journal of Business Research 33: 91-101.

Makadok R. 2001. Toward a synthesis of the resourcebased and dynamic-capability views of rent creation. Strategic Management Journal 22(5): 387-402.

Makadok R. 2003. Doing the right thing and knowing the right thing to do: why the whole is greater than the sum of the parts. Strategic Management Journal, Special Issue 24: 1043-1055.

Martins MR. 1995. Size of municipalities, efficiency, and citizen participation: a cross-European perspective. Environment and Planning C: Government and Policy 13(4): 441-458.

Meyer JP, Allen NJ. 1997. Commitment in the Workplace: Theory, Research and Application. Sage: Thousand Oaks, CA.

McGuire J, Sundgren A, Schneeweiss T. 1988. Corporate social responsibility and firm financial performance. Academy of Management Journal 31(4): 854-872.

Miller C, Burke L, Glick W. 1998. Cognitive diversity among upper-echelon executives: implications for strategic decision processes. Strategic Management Journal 19(1): 39-58.

Miller D, Droge C. 1986. Psychological and traditional determinants of structure. Administrative Science Quarterly 31: 539-560.

Milliken FJ. 1987. Three types of perceived uncertainty about the environment: state, effect, and response uncertainty. Academy of Management Review 12: $133-143$.

Ministry of Interior. 1999. Report of Auditing Financial Data Local Authorities 1998 (no. 4) (in Hebrew). Ministry of Interior: Jerusalem.

Moore MH. 1995. Creating Public Value: Strategic Management in Government, Harvard University Press: Cambridge, MA.

Moore MH. 2000. Managing for value: organizational strategy in for-profit, nonprofit, and governmental organizations. Nonprofit and Voluntary Sector Quarterly 29(Suppl.): 183-204.

National Academy of Public Administration. 1999. A Government to Trust and Respect: Rebuilding Citizen-Government Relations for the 21st Century. A report on civic trust and citizen responsibility 
(June), National Academy of Public Administration: Washington, DC.

Norburn D, Birley S. 1988. The top management team and corporate performance. Strategic Management Journal 9(3): 225-237.

OECD. 2001. The New Economy: Beyond the Hype. The OECD Growth Project, Economics: Paris.

O'Reilly III CA, Pfeffer J. 2000. Hidden Value: How Great Companies Achieve Extraordinary Results with Ordinary People. Harvard Business School Press: Boston, MA.

O'Reilly CA, Snyder RC, Boothe JN. 1993. Executive team demography and organizational change. In Organizational Change and Redesign: Ideas and Insights for Improving Performance, Huber GP, Glick WH (eds). Oxford University Press: New York; 147-175.

Penrose ET. 1959. The Theory of the Growth of the Firm. Basil Blackwell: Oxford.

Peteraf MA. 1993. The cornerstones of competitive advantage: a resource-based view. Strategic Management Journal 14(3): 179-191.

Peterson P. 1981. City Limits. University of Chicago Press: Chicago, IL.

Pfeffer J. 1994. Competitive Advantage Through People: Unleashing the Power of the Work Force. Harvard Business School Press: Boston, MA.

Porter ME. 1985. Competitive Advantage. Free Press: New York.

Porter ME. 1996. What is strategy? Harvard Business Review 74(6): 61-78.

Porter ME. 1998. On Competition. Harvard Business School Press: Boston, MA.

Prahalad CK, Hamel G. 1990. The core competence of the corporation. Harvard Business Review 68(3): 79-91.

Priem RL, Butler JE. 2001. Is the resource-based 'view' a useful perspective for strategic management research? Academy of Management Review 26(1): 22-40.

Propper C, Halonen M. 1999. The allocation of effort in government bureaucracies. A paper presented at the Royal Economic Society's 1999 Annual Conference at the University of Nottingham.

Reed R, DeFillippi RJ. 1990. Causal ambiguity, barriers to imitation, and sustainable competitive advantage. Academy of Management Review 15(1): 88-102.

Rivkin JW. 2000. Imitation of complex strategies. Management Science 46(6): 824-844.

Roberts PW, Dowling GR. 2002. Corporate reputation and sustained superior financial performance. Strategic Management Journal 23(12): 1077-1093.

Robins J, Wiersema MF. 1995. A resource-based approach to the multibusiness firm: empirical analysis of portfolio interrelationships and corporate financial performance. Strategic Management Journal 16(4): 277-299.

Schneider M. 1989. Intermunicipal competition, budgetmaximizing bureaucrats, and the level of suburban competition. American Journal of Political Science 33(3): 612-628.

Schultz TW. 1961. Investment in human capital. American Economic Review 51(1): 1-17.
Shrum W, Wuthnow R. 1988. Reputational status of organizations in technical systems. American Journal of Sociology 93(4): 882-912.

Siggelkow N. 2002. Evolution toward fit. Administrative Science Quarterly 47(1): 125-159.

Smidts A, Pruyn ATH, van Riel CBM. 2001. The impact of employee communication and perceived external prestige on organizational identification. Academy of Management Journal 44(5): 1051-1062.

Smith S. 1990. America's most admired corporations. Fortune (1 January): 30-46.

Spector R, McCarthy PD. 1995. The Nordstrom Way: The Inside Story of America's \#1 Customer Service Company. Wiley: New York.

Stalk G, Evans P, Shulman LE. 1992. Competing on capabilities: the new rules of corporate strategy. Harvard Business Review 70(2): 57-67.

Tam A. 2003. Robust canonical analysis (RCA): identifying the most important variables in a twoset multivariate problem. MSc thesis, Faculty of Management, Tel Aviv University.

Teece DJ. 2000. Strategies for managing knowledge assets: the role of firm structure and industrial context. Long Range Planning 33(1): 35-54.

Tiebout CM. 1956. A pure theory of local expenditures. Journal of Political Economy 64: 416-424.

Timm NH. 1975. Multivariate Analysis with Application in Education and Psychology. Brooks: Belmont, CA.

Tishler A, Dvir D, Shenhar A, Lipovetsky S. 1996. Identifying critical success factors of defense development projects: a multivariate analysis. Technological Forecasting and Social Change 51(2): 151-171.

Tishler A, Lipovetsky S. 2000. Modeling and forecasting with robust canonical analysis: method and application. Computers and Operations Research 27: 217-232.

Wagner FR, Morse JJ. 1975. A measure of individual sense of competence. Psychological Reports 36: 451-459.

Waldman DA, Ramirez GG, House RJ, Furanam P. 2001. Does leadership matter? CEO leadership attributes and profitability under conditions of perceived environmental uncertainty. Academy of Management Journal 44(1): 134-143.

Weigelt K, Camerer C. 1988. Reputation and corporate strategy: a review of recent theory and applications. Strategic Management Journal 9(5): 443-454.

Wernerfelt B. 1984. The resource-based view of the firm. Strategic Management Journal 5(2): 171-180.

Yukl GA. 1981. Leadership in Organizations. PrenticeHall: Englewood Cliffs, NJ.

\section{APPENDIX 1: MEASUREMENT ITEMS FOR THE INTANGIBLE ELEMENTS}

\section{Managerial capabilities}

1. Attracting and retaining well-trained and competent top managers.

2. Achieving a better overall control of general organization performance. 
3. Perceiving new organizational opportunities and potential threats.

4. Developing and communicating a unified sense of direction and a sense of common purpose to which all members of the organization can relate.

5. Unifying conflicting opinions, improve coordination and enhance effective collaboration between key executives, generate enthusiasm and motivate sufficient managerial drive for better performance.

6. Developing a more effective organizationwide strategic planning system for planned overall organizational development.

7. Generating advanced developmental and training programs for our organizational members.

8. Increased use of management by objective.

9. Increased use of 'financial accountability.'

10. Increased participative decision making at senior and middle management levels.

11. An extensive and effective use of quantitative techniques in decision making.

12. An extensive use of cost-effective analyses.

\section{Human capital}

1. Employees have suitable education to fulfill their jobs.

2. Employees are well trained.

3. Employees hold suitable work experience for accomplishing their job successfully.

4. Employees are well-skilled professionally to accomplish their job successfully.

5. No one knows this job better than our employees.

6. Problems here are easy to solve once the employees understand the various consequences of their actions, a skill they have acquired.

7. Employees do not know why, but sometimes when they are supposed to be in control they feel they are being manipulated (reversescored item).

8. If anyone here can find the answer, it is our employees.

9. Employees go home the same way they arrived in the morning, feeling they have not accomplished much (reverse-scored item).

10. Considering the time spent on the job, employees feel thoroughly familiar with their tasks.

11. Doing this job well is a reward in itself.

12. Mastering their jobs meant a lot to our employees.

\section{Internal auditing}

1. The internal auditing helps to a better functioning of the organizational members.

2. The internal auditing clarifies aspects of working processes.

3. The internal auditing is perceived as a threat to the position and status of the employees' (reverse-scored item).

4. Organizational members are not afraid of the results revealed by the internal auditing.

5. The internal auditing prevents inappropriate actions which may harm the organization.

6. The internal auditing helps achieve the organizational goals.

\section{Labor relations}

1. There is complete trust between management and employees.

2. There is complete satisfaction of the relationships between management and employees.

3. There is a clear and accepted managerial policy on all parts (management and employees) regarding labor relations system.

4. There is a constant consultation between management and employees.

5. There are mutual respect and good intentions between management and employees.

6. The principle of security, namely caring for the employee's health, safety, livelihood, and her future employment, is a common one among both management and employees.

7. The principle of fairness, namely caring that the employee is getting fair compensation for her effort and contribution, is a common one among both management and employees.

8. The principle of individualism, namely caring that the employee is making meaningful work independently, on the basis of her planning and reasonable performance, is a common one among both management and employees.

9. The principle of democracy, namely caring that the employee participates actively in the decision making, is a common one among both management and employees.

\section{Organizational culture}

1. There is a high involvement of the employees in the processes, decisions, and their implementation.

2. The employees are committed and hold a high sense of responsibility to the organization. 
3. All have a common set of values, creeds, and symbols.

4. There is a high coordination and agreement among the employees.

5. The organization knows the external environment and provides appropriate responses.

6. The organization adapts its structure and the way it functions to changes in the external environment.

7. The organizational goals are clear and agreeable to all members.

8. The organization strives hard to achieve its goals.

\section{Perceived organizational reputation}

1. The quality of management of my local authority is credited with a very favorable reputation.

2. The ability of my local authority to attract, develop, and keep talented people is credited with a very favorable reputation.

3 . The quality of services my local authority supplies is credited with a very favorable reputation.

4. The financial soundness of my local authority is credited with a very favorable reputation.

5. In my local authority, the education system is credited with a very favorable reputation.

6. In my local authority, the municipal facilities are credited with a very favorable reputation.

7. In my local authority, the tax system is credited with a very favorable reputation.

8. In my local authority, the transportation system is credited with a very favorable reputation.

9. The quality of life in my local authority's jurisdiction is credited with a very favorable reputation.'

\section{APPENDIX 2: A BRIEF DESCRIPTION OF THE RCA METHOD}

Suppose that we are given two sets of data, each organized in a matrix, as follows: $X_{i j}, i=1, \ldots, l$; $j=1, \ldots, n$, and $Y_{i j}, i=1, \ldots, l ; j=1, \ldots, m$. In the field of management, each data set may include a group of specific variables describing various attributes of $l$ projects or assessments of $l$ individuals. For example, $X$ may represent data on $n$ variables describing the managerial structure of projects, and $Y$ may contain $m$ different measures of success (see Tishler et al., 1996). For ease of presentation, suppose that all variables are standardized (variables are standardized by subtracting their mean and dividing them by their standard deviations). Define the scores of the two data sets as follows:

$$
\eta=X a, \xi=Y b
$$

where $a$ and $b$ are $(n \times 1)$ and $(m \times 1)$ vectors of constant weights (parameters). The $(l \times 1)$ vectors of scores $\eta$ and $\xi$ can be interpreted as the weighted averages of their respective matrices (sets of variables). For example, $\xi$ includes the average of project success across all projects; that is, a relatively high value of $\xi_{1}$ means that project 1 is very successful, relative to other projects in the sample. In this paper we try to find the relations, or connections, between data sets $X$ and $Y$ by means of the weighted averages ('aggregators') $\eta$ and $\xi$; that is, we say that $X$ and $Y$ are closely related to each other if $\eta$ and $\xi$ are 'close' to each other. Clearly, the weights $a$ and $b$ may have managerial or other meanings that should be taken into account in the analysis.

RCA uses covariance as the measure of connection between two data sets; that is, rather than maximizing the correlation (as is the case with canonical correlations analysis) RCA seeks to estimate $a$ and $b$ that maximize the following sample covariance:

$$
\operatorname{cov}(\xi, \eta)=\xi^{\prime} \eta=a^{\prime} X^{\prime} Y b
$$

with the usual normalizing conditions $a^{\prime} a=1$ and $b^{\prime} b=1$. Thus, applying the RCA method to two data sets amounts to estimating the weights which maximize the covariance between linear aggregators (weighted averages) of the two data sets. RCA is applied to standardized variables. Thus, a variable with a large estimated weight affects the connection between the two data sets more than a variable with a small weight. Variables in one data set are defined as critical (important) relative to those in the second data set when their weights in the RCA between the two data sets are large (see Tishler et al., 1996; Tishler and Lipovetsky, 2000) for algorithms that select critical variables from large data sets. Variables that are not designated as critical relative to the other data set may still affect this set. However, their influence on the second data set may not be as pronounced as the influence of critical variables. 
Tishler and Lipovetsky (2000) show that the RCA estimates (the estimated vectors $a$ and $b$ ) can also be obtained as a least squares (LS) approximation of $R_{x y} \equiv X^{\prime} Y$, the matrix of correlations among the variables in the two data sets. That is:

$$
R_{x y}=\lambda b a^{\prime}+\varepsilon
$$

where $\lambda$ is a scalar and $\varepsilon$ is a matrix of residuals. The LS function of the residuals is

$$
L S=\|\varepsilon\|^{2}=\left\|R_{x y}-\lambda b a^{\prime}\right\|^{2}
$$

The RCA estimates $a$ and $b$ are obtained for $\lambda_{\max }$, the maximal eigenvalue of $R_{x y}$. At the optimum:

$$
L S=\left\|R_{x y}\right\|^{2}-\lambda_{\max }^{2}=\left\|R_{x y}\right\|^{2}\left(1-\frac{\lambda_{\max }^{2}}{\left\|R_{x y}\right\|^{2}}\right)
$$

Thus, the goodness of fit of the RCA estimates, where $r_{i j}$ is the simple correlation between $x_{i}$ and $y_{j}$, is as follows:

$$
q^{2} \equiv \frac{\lambda_{\max }^{2}}{\left\|R_{x y}\right\|^{2}}=\frac{\lambda_{\max }^{2}}{\sum_{i=1}^{n} \sum_{j=1}^{m} r_{i j}^{2}}, \quad 0 \leq q^{2} \leq 1
$$

The measure $q^{2}$, which measures the share of the explained variability in the total variability among the correlations of the variables in the two data sets, is equivalent to the well-known $R^{2}$ in a regression model. Finally, the squared canonical correlation among the critical variables, $r_{C C}^{2}$, which, like forecasting with the RCA method, uses all the correlations among the critical variables is also an important measure of goodness of fit of the final RCA model (see Tishler and Lipovetsky, 2000; Tam, 2003). 